\title{
Análise da nova gestão do conhecimento: perspectivas para abordagens críticas
}

\section{Luiz Fernando de Barros Campos}

\section{Engenheiro Eletricista pela UFMG; Especialista em Gestão Estratégica da Informação pela ECI-UFMG; Mestrando em Ciência da Informação pela ECI- UFMG.}

Apresenta a Nova Gestão do Conhecimento, um modelo desenvolvido pelos consultores norte-americanos Joseph $M$. Firestone e Mark W. McElroy do Knowledge Management Consortium Internacional (KMCI), e o ciclo de vida do conhecimento associado. Procura-se explorar os conceitos básicos e estabelecer um diálogo com obras mais proeminentes das disciplinas de Gestão do Conhecimento e Capital Intelectual. São enfocados vários temas em suas relações com o modelo apresentado, como criação de sentido, cultura, estratégia, Capital Intelectual e melhores práticas. Com base na caracterização do modelo, alguns de seus aspectos são criticados e, em seguida, são delineadas questões metodológicas para uma abordagem crítica, mais descritiva e menos normativa, na área da Gestão do Conhecimento.

Palavras-Chave: Nova Gestão do conhecimento; Firestone \& McElroy; Gestão do conhecimento; Capital intelectual

\section{Analysis of The New Knowledge Management: Perspectives for critical approaches}

The articles presents The New Knowledge Management, a model developed by the North-American consultants Joseph M. Firestone and Mark W. McElroy, leaders of the Knowledge Management Consortium International (KMCI), and the associated Knowledge Life Cycle. It is attempted to explore the basic concepts and to establish a dialogue with preeminent works of the disciplines Knowledge Management and Intellectual Capital. Various subjects are related to the model showed, such as sense-making, culture, strategy, Intellectual Capital and best practices. 
Based on the characterization of the model, some of its aspects are criticized. Then, possibilities for a more descriptive and less normative critical approach in the field of Knowledge Management are outlined.

Key-words: The New Knowledge Managemen; Firestone e McElro; Knowledge Management; Intellectual Capital.

Recebido em 31.07.2006 Aceito em 28.02.2007

\section{Introdução}

A Nova Gestão do conhecimento - NGC - é a designação para o conjunto de temas, práticas e modelos que enfatizam a integração do conhecimento (compartilhamento, divulgação, recuperação e ensino), assim como sua produção e geração. Essa teoria foi desenvolvida pelos autores Joseph M. Firestone e Mark W. McElroy, consultores e sócios fundadores do Consórcio Internacional de Gestão do conhecimento ${ }^{1}$, com base no trabalho inicial de McElroy (1999). Suas obras mais representativas são McElroy (2002), Firestone (2003) e, notadamente, Firestone e McElroy (2001).

O modelo desses autores foi escolhido por representar um trabalho atual da Gestão do conhecimento, revelador de tendências contemporâneas, e apresentar tom pragmático e almejada aplicabilidade pelas organizações, mas sem descuidar do rigor na fundamentação teórica. Influenciaram na escolha a complexidade e abrangência do modelo, a completude da exposição, a fundamentação interdisciplinar com o apoio de teorias de filósofos (destacadamente, Popper) e as críticas e diálogos constantes com teorias e modelos consagrados da Gestão de conhecimento e Capital intelectual.

Este trabalho procura apresentar resumidamente os pontos fundamentais da teoria, relacionando-os, sempre que adequado, implícita ou explicitamente, com idéias de obras consideradas fundamentais da área da Gestão do conhecimento e Capital intelectual (com base na análise bibliográfica de SERENKO e BONTIS, 2004), especialmente Davenport e Prusak (1998), Leonard-Barton (1998), Nonaka e Takeuchi (1997), Stewart (1998) e Sveiby (1998). São apontados no modelo e empregados em sua análise alguns aspectos metodológicos de construção e exposição da teoria. Pretende-se que a metodologia esboçada contribua para a constituição de perspectiva mais crítica e menos utilitária para a análise de trabalhos na área da Gestão de conhecimento, em que se valorizem os fundamentos e os aspectos explicativos.

O texto estrutura-se do seguinte modo: inicialmente, são expostos os conceitos empregados de dados, informação e conhecimento. A seguir, é descrito o ciclo de vida do conhecimento, o que torna possível a

1 Knowledge Management Consortium Internacional (KMCI), em www.kmci.org. 
caracterização da NGC e de suas fases. São então estabelecidas implicações do modelo para a estratégia e cultura organizacionais, a criação de sentido, as melhores práticas e a disciplina Capital intelectual. Caracterizado o modelo, a teoria exposta é avaliada com base em sua metodologia e suas idéias fundadoras, ressaltando alguns pontos passíveis de fundamentar uma análise mais aprofundada das obras discutidas, assim como questões metodológicas decorrentes.

\section{As definições fundamentais - dados, informação e conhecimento}

Com base em Popper (2000) e entre outras obras do pensador, Firestone e McElroy distinguem três tipos de conhecimento. $O$ conhecimento do Mundo 1 está representado ou codificado em objetos ou estruturas físicas; é o mundo material do conhecimento. O conhecimento do Mundo 2 refere-se a crenças ou a predisposições de crenças sobre o mundo, o belo (ética) e o justo (moral); é o mundo mental do conhecimento. Já o conhecimento do mundo 3, o mundo autônomo dos objetos mentais, engloba as formulações lingüísticas compartilháveis, as teorias, os modelos e os postulados de conhecimento sobre o mundo, sobre o belo e sobre o justo.

Várias definições usuais de conhecimento são discutidas. A mais comum delas é crença verdadeira justificada, definição adotada por Nonaka e Takeuchi (1997) e considerada do Mundo 2. O argumento, em síntese, é de que não é possível a justificação do conhecimento, já que nunca há evidências suficientes para provar a veracidade ou falsidade de um postulado do conhecimento. A própria crítica de Gettier (1963) baseiase no conceito de justificação. Como se verá pela definição dos autores, há, em conseqüência, o questionamento e relativização do conceito de verdade, para além de uma abordagem estritamente realista ou idealista.

A definição de conhecimento como informação em contexto (do Mundo 3) é considerada lingüística devido ao termo informação não ser freqüentemente utilizado para designar as crenças e predisposições do Mundo 2. Fundamentalmente, não há, nessa definição, distinção entre informação e conhecimento, aspecto demonstrável pela impossibilidade de haver informação fora de contexto. A definição é racionalista (só tem sentido em um espaço dedutivo, o contexto) e pragmática (só há utilidade no contexto).

São igualmente discutidas as freqüentes definições de conhecimento que o relacionam com ação, como em Sveiby (1998), capacidade para ação. Mesmo que o conhecimento seja necessário para a ação, ele não é suficiente, já que são também imprescindíveis a intenção para o ato e a capacidade ou poder para efetivá-lo. Conceitos de conhecimento polarizados em torno da idéia de compartilhamento (como informação que pode ser comunicada ou compartilhada) são rebatidos pela própria caracterização da concepção de compartilhamento: as crenças do Mundo 2 não podem ser partilhadas, já que se supõe haver um hiato epistêmico 
entre o Mundo 2 e o 3, só se admitindo a existência de compartilhamento de objetos mentais do Mundo 3.

Dado é definido por Firestone e McElroy como um valor observável, mensurável ou calculável de um atributo. O contexto (sempre existente) é que torna compreensível a estrutura do formato de um dado. A informação é sempre provida por um dado; dado é um tipo de informação. Em termos gerais, informação é definida como dado mais compromissos e interpretações, ou esses compromissos e interpretações sozinhos (só informação). O conhecimento (organizacional) é definido como informação que passou por testes e avaliações em processos que procuram eliminar erros e alcançar a verdade, portanto mais confiável e aprimorada por registros e experiências. Assim, esse conhecimento organizacional é um subconjunto de informação. A tradicional pirâmide (dado, informação, conhecimento, sabedoria) é implodida: só se pode imaginar ciclos em que dados e conhecimento (tipos de informação) são gerados a partir de só informação (compromissos e interpretações), conhecimento, dados e problemas, como mostra a FIG. 1.

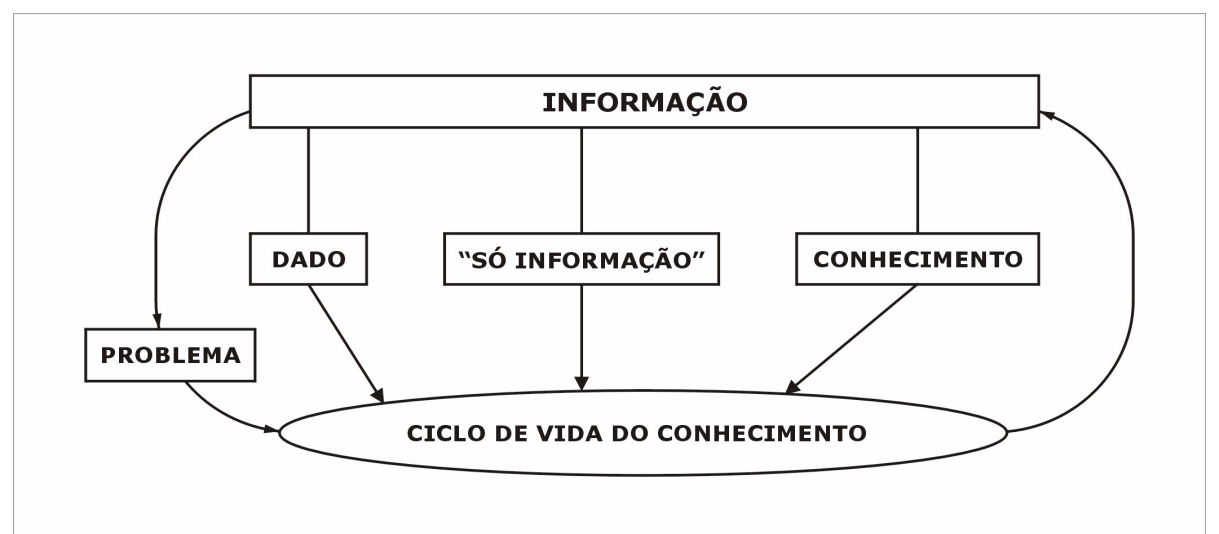

FIGURA 1 - Os conceitos em ciclos e o descarte da tradicional pirâmide de dados, informação e conhecimento.

Fonte: Adaptado de Firestone e Mcelroy (2001, p. 108)

Dessa forma, trabalha-se explicitamente com a idéia de que o conhecimento organizacional é objetivo e pertence ao Mundo 3. Admite-se um conhecimento do Mundo 2 que passa pelos mesmos processos de validação e é falível, mas que é pessoal e psicológico (subjetivo), logo não diretamente comunicável. A objetividade dos postulados de conhecimento do Mundo 3 não depende de sua verdade (objetiva), mas dos processos de validação que exigem a explicitação e compartilhamento desses postulados, assim como dos próprios critérios de validação.

A distinção entre o Mundo 2 e o Mundo 3, assim como o uso do termo conhecimento para objetos mentais do Mundo 3, é freqüentemente contestada. Uma objeção seria: expressões de conhecimento do Mundo 3 não são o mesmo que conhecimento do Mundo 2, mas sim vestígios do conhecimento. Denominá-las conhecimento é o mesmo que confundir sombras de objetos com os próprios objetos (o que, realmente, constitui 
um argumento de fundo platônico facilmente reconhecível). Essas críticas são respondidas: afirma-se não haver confusão entre conhecimento do Mundo 2 e do 3 ; o primeiro é usualmente não redutível à linguagem, habitualmente predisposicional e inconsciente, não partilhável. $E$, principalmente, os postulados de conhecimento do Mundo 3 não são expressões de crenças de conhecimento do Mundo 2. Esses postulados são criados no esforço de resolver problemas. O que se pode analisar, contestar, compartilhar é o que é dito (expresso), não aquilo que é pensado ou acreditado. A verdade, considerada como um construto filosófico, é uma relação entre entidades lingüísticas e fatos (não entre crenças ou predisposições e fatos). Por fim, os postulados de conhecimento não são vestígios, pois são criados não só a partir de crenças, mas também de criatividade e esforço pessoais, forças situacionais, estruturas culturais e sociais e interações diversas.

\section{0 modelo do ciclo de vida do conhecimento}

Os autores concebem um ciclo de execução decisória que é motivado por um hiato percebido entre um estado atual de objetivos de um agente e o estado atual do mundo que o agente está tentando gerenciar. O ciclo é um comportamento instrumental que visa suprimir esse hiato percebido.

O ciclo de execução decisória é composto das fases de planejamento, ação, monitoração e avaliação. Planejamento é uma atividade de produção e integração de conhecimento. Envolve determinar prioridades, metas, objetivos, realizar previsões e análises de custo/benefício, assim como revisar um processo de trabalho ou efetuar sua reengenharia. Gera um plano, uma instância do Mundo 3. A ação significa realizar o processo do domínio do negócio ou um de seus componentes. Envolve a utilização do plano junto com conhecimento do Mundo 2 e 3, mas não produz novo conhecimento.

A monitoração é o acompanhamento e a descrição retrospectiva das atividades e seus produtos. Abarca a coleta de dados e informações, as modelagens de processos e o uso de conhecimento prévio para produzir novo conhecimento prognóstico e descritivo. É uma atividade de produção e integração de conhecimento, agora do Mundo 2 e 3.

Por fim, a avaliação implica a utilização dos resultados da monitoração com conhecimento prévio a fim de medir os resultados da ação na supressão dos hiatos motivacionais e avaliar os impactos nos processos de negócio. É outra atividade que produz e integra conhecimento do Mundo 2 e 3.

Mas de onde vem o conhecimento utilizado nos ciclos de execução decisória? Da base de conhecimento organizacional distribuída, uma combinação de crenças e de predisposições de crenças (Mundo 2) dos agentes dos empreendimentos e de postulados de conhecimento validados baseados em artefatos, e ainda de metapostulados, armazenados em repositórios eletrônicos e não eletrônicos (Mundo 3). A base de conhecimento encerra todas as estruturas que incorporam conhecimento 
organizacional, como processos de negócios, planos, expressões da cultura organizacional, estratégia organizacional, políticas, procedimentos e sistemas de informação.

Firestone e McElroy tomam emprestada a teoria de aprendizagem organizacional de circuitos único e duplo de Argyris e Schön. Conforme Argyris (1999), Choo (1998) e Firestone e McElroy (2001), na aprendizagem de circuito único, a ação organizacional é corrigida quando ocorrem resultados não esperados e modificações no ambiente (que constituem um sistema de retroalimentação), mas as normas de desempenho vigentes são mantidas assim como as estratégias associadas. Novo conhecimento é produzido para ajustamento a ações, mas o processo não apresenta hiatos epistêmicos (problemas). 0 mesmo não ocorre na aprendizagem de circuito duplo, quando a correção do erro requer a reestruturação das normas, estratégias e pressupostos. Este tipo de aprendizado não é somente adaptativo, como o anterior, mas generativo e, na maioria dos casos, conflituoso.

Os autores criam um modelo de aprendizagem baseado no modelo apresentado de aprendizagem de circuitos simples e duplo e nas idéias de Popper (POPPER, 2000). Basicamente, o ponto destacado (e de conexão entre os modelos) é que o circuito de ciclo duplo recai no esquema tetrádico de Popper. Esse esquema é uma visão de produção de conhecimento por tentativa e erro (conjecturas e refutações). O processo de ciclo duplo começa com um problema, que motiva uma tentativa de solução, que então é testada, avaliada e possivelmente refutada de modo a efetuar eliminação de erros. Novos problemas motivam outros ciclos e a constante reavaliação do conhecimento.

Assim, conhecimento é produzido em um ciclo de execução decisória por meio de um processo de ciclo único ou por meio de ciclos de vida de problemas, que constituem um circuito duplo. O ciclo de vida de problemas é entendido como um processo de conhecimento composto de muitos ciclos de execução decisória, motivado por um hiato epistêmico (problema).

Outra questão argüida, fundamental para o modelo dos autores, é a concepção do comportamento dos agentes organizacionais nos processos de negócios. O modelo utilizado é o de uma rede de processos comportamentais. Os agentes dirigidos por metas operam em ciclos de execução decisória, influenciados por dimensões como memória, valores, atitudes, orientações situacionais, objetivos. Esses ciclos decisórios integram as transações e interações dos agentes e são influenciados por outras transações e por uma ecologia social, que engloba fatores sociais, culturais, geográficos e econômicos, como esquematizado na FIG. 2. 


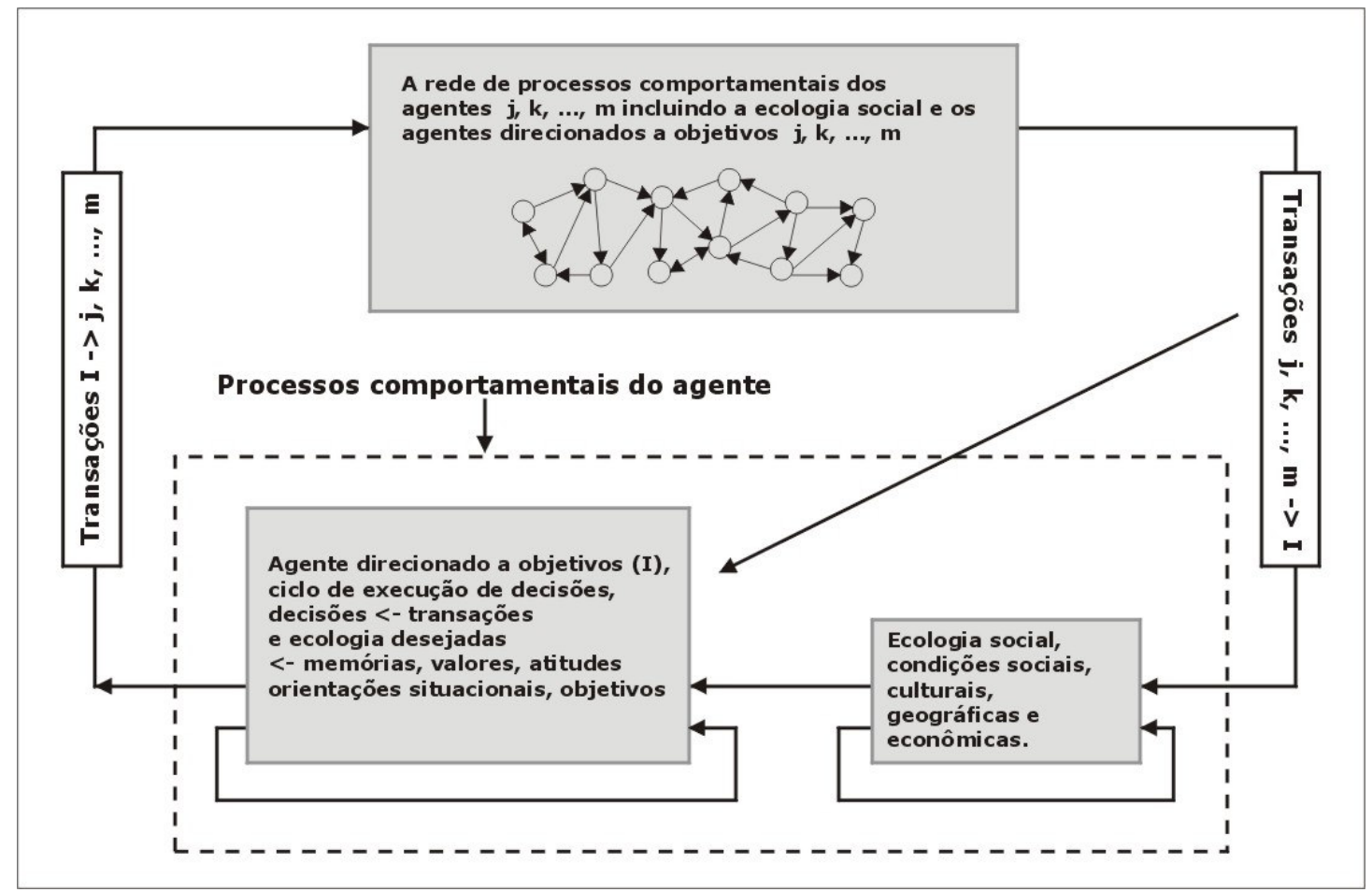

FIGURA 2 - O modelo transacional compreende os fluxos de comportamentos entre agentes.

Fonte: Adaptado de Firestone e Mcelroy (2001 p. 24)

O destaque é que há uma extrapolação benéfica do modelo $\mathrm{SECI}^{2}$ de Nonaka e Takeuchi (1997), situacionalmente orientado. As crenças são basicamente cognições, ou cognições combinadas com avaliações, e ambas representam orientações psicológicas situacionais, e não predisposições psicológicas mais gerais. Desse modo, argumenta-se que a literatura sobre Gestão do conhecimento não reconhece adequadamente as predisposições de conhecimento do Mundo 2, produzidas nas experiências dos agentes e motivadoras das decisões nos processos de conhecimento. No esquema de Firestone e McElroy, as motivações psicológicas dos indivíduos ou a cultura de agentes grupais são definidas por orientações de valores, predisposições de atitudes e tendências de consecução das metas, em um processo recursivo e de muitos níveis. Estímulos externos envolvem as transações (interações) e a ecologia social.

Outro ponto a destacar é que os ciclos de execução decisória são operados imediatamente sob crenças e disposições do Mundo 2 e mediatamente sob os postulados de conhecimento do Mundo 3. Ou seja, o precursor imediato das decisões, ações, transações e interações é o Mundo 2 (crenças, predisposições, emoções), mediado pelo Mundo 3 de idéias, conceitos, modelos e teorias objetivizados.

2 O acrônimo origina-se dos modos de conversão do conhecimento, base da criação do conhecimento no modelo de Nonaka e Takeuchi, que são a Socialização (conversão de conhecimento tácito para tácito), a Externalização (tácito para explícito), a Combinação (explícito para explícito) e a Internalização (explícito para tácito). 
Com base nas idéias apresentadas é possível agora descrever o esquema do ciclo de vida do conhecimento dos autores, cujo diagrama é mostrado na FIG. 3. Há dois processos centrais: a produção de conhecimento e a integração de conhecimento. A produção de conhecimento envolve o aprendizado individual e grupal, a aquisição de informação, a formulação de postulados de conhecimento, sua codificação e validação. Como resultado desse módulo são produzidos postulados de conhecimento codificados, falsificados e sobreviventes, assim como os correspondentes metapostulados de conhecimento, todos componentes do conhecimento organizacional, que deve ser integrado. A integração do conhecimento engloba o ensino, o compartilhamento, a disseminação e a busca. O conhecimento integrado compõe a base de conhecimentos, fonte e destino final dos processos que utilizam o conhecimento, ou seja, todos os processos comportamentais de negócios dos agentes interativos. Os processos de negócios são compostos por ciclos de execução decisória. Esses ciclos produzem conhecimento regulatório. Quando esse conhecimento regulatório falha, um processo de tentativa e erro se inicia, o ciclo de vida de problemas, que, por sua vez, é composto de muitos ciclos decisórios, motivado pelo sistema de incentivos de aprendizagem (a hierarquia motivacional - predisposições de orientações situacionais e valores) e direcionado para o fechamento do hiato epistêmico, o problema detonador do ciclo. Vê-se que o ciclo de vida do conhecimento é um ciclo de vida de problemas no contexto organizacional, formado de vários ciclos decisórios, que podem gerar seus novos problemas e originar ciclos de conhecimento de diversos níveis.

O modelo de Nonaka e Takeuchi (1997) é ainda criticado em outros pontos. É contestada a apropriação de concepções de Polanyi (1958, 1967), como o conceito de conhecimento tácito, por Nonaka e Takeuchi. O conhecimento tácito é considerado de explicitação impossível. Assim, o conhecimento não explicitado, mas passível de externalização, é denominado implícito ${ }^{3}$. Com a introdução dos conceitos de conhecimento subjetivo (nas mentes) e objetivo (nos artefatos), o número de categorias passível de conversão passa de duas a cinco, já que a categoria de conhecimento tácito objetivo, ou conhecimento tácito existente fora das mentes, é considerada inexistente.

3 Outros autores adotam a mesma categorização, como Wilson (2002). 


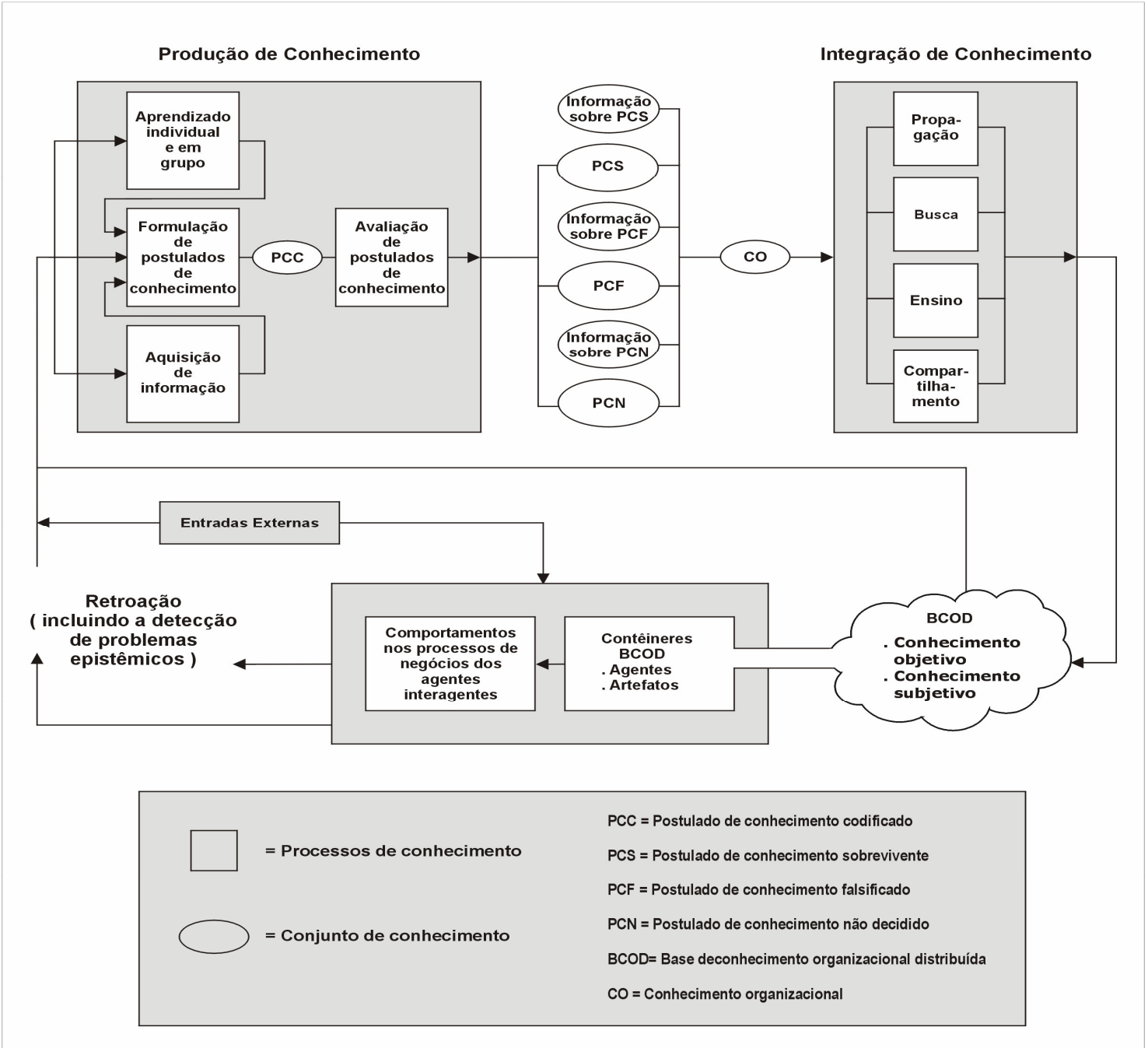

FIGURA 3 - Modelo do ciclo de vida do conhecimento.

Fonte: Adaptado de Firestone e McElroy (2001, p. 52)

\section{A Nova Gestão do conhecimento}

Firestone e McElroy analisam e criticam as abordagens históricas de gerações de Gestão de conhecimento de Koenig e Snowden e criam a sua própria.

Koenig (2002) concebe três estágios da Gestão de conhecimento. O primeiro estágio era baseado primariamente em tecnologia da informação e objetivava o compartilhamento e a coordenação do conhecimento em um empreendimento. $O$ segundo estágio era primordialmente 0 reconhecimento da insuficiência da aplicação de tecnologia e a mudança de foco para os fatores culturais e humanos, com destaque para as obras de Senge (1990) e Nonaka e Takeuchi (1997) e a atuação de comunidades de prática. $O$ atual e terceiro estágio valoriza a importância do conteúdo, seu arranjo, descrição, estrutura e recuperação. O objetivo é obter conteúdos relevantes desenvolvendo taxonomias e gerindo o conteúdo. 
Snowden (2002) idealiza dois estágios e um hipotético futuro terceiro estágio. O primeiro era baseado em informação para a tomada de decisão, problematizando o conceito de conhecimento apenas em sua parte final e enfatizando a reengenharia dos processos de negócios. $O$ segundo é baseado em uma popularização do modelo de Nonaka e Takeuchi, considerado o precursor da Gestão do conhecimento, mas insere a crítica do dualismo na concepção de conhecimento tácito e explícito em detrimento de uma visão dialética. O terceiro estágio, ainda por vir, seria caracterizado pela visão paradoxal de conhecimento como coisa e processo, pela centralidade dos conceitos de contexto, narrativa e gestão de conteúdo, pelo entendimento da organização como um sistema adaptativo complexo e pela aplicação de modelos mecânicos apenas em determinadas situações, ocorrendo a utilização da teoria do caos e da complexidade em outras situações consideradas adequadas.

A crítica de Firestone e McElroy a esses autores apóia-se fundamentalmente no argumento de que suas cronologias estariam muito mais embasadas em uma história de publicações e ferramentas do que em um modelo conceitual de suporte da periodização. O terceiro estágio de Snowden, inclusive pelas similaridades com o modelo dos autores, é discutido detalhadamente (FIRESTONE e McELROY, 2001, p. 104-134).

O debate abre caminho para a apresentação da periodização dos autores (McELROY, 1999, 2002; FIRESTONE e McELROY, 2001). Há dois estágios na história da disciplina Gestão do conhecimento. O primeiro é visto como enfatizando primordialmente a integração do conhecimento, com ênfase no lado da oferta do conhecimento. A segunda geração enfatiza simultaneamente o lado da oferta e o lado da demanda, a produção do conhecimento. A NGC faz parte da segunda geração e seu modelo de trabalho básico é o ciclo de vida do conhecimento.

Três argumentações são primordiais para o entendimento da NGC. A primeira delas é que é efetuada uma distinção entre processamento de conhecimento e gestão de conhecimento. Para os autores, essa distinção é considerada normalmente desprezada na literatura de Gestão de conhecimento e sua ausência gera confusão. Todas as organizações efetuam processamento de conhecimento. Isso é representado no ciclo de vida do conhecimento, em relação e participação direta com os processos de negócio (nível zero). O processamento de conhecimento é uma atividade contínua e persistente pela qual os agentes gerenciam (manipulam, controlam, organizam, facilitam) outros agentes, componentes, artefatos e atividades de produção e integração de conhecimento, com o propósito de criar, manter e compartilhar uma base orgânica e unificada de conhecimento. Já a Gestão de conhecimento é uma disciplina que procura aprimorar esses processos de conhecimento, ou seja, é gestão de processos de conhecimento. Ciclos de vida de conhecimento formam-se visando criar conhecimento que possibilite os processos de produção e integração de conhecimento no nível zero. Esse é o nível um. Níveis superiores podem formar-se e são caracterizados como metaníveis, sempre endereçando conhecimento sobre como produzir 
conhecimento para nível inferior (eventualmente para o próprio nível), como ilustrado na FIG.4.

A segunda argumentação é o estabelecimento da diferença fundamental entre Gestão de conhecimento e Gestão de informação, derivada das próprias definições de informação e conhecimento. Gestão de conhecimento é uma forma de Gestão de informação. O aspecto mais imediato é que Gestão de conhecimento foca a informação validada (conhecimento). O fator tipificador da Gestão de conhecimento é o gerenciamento de uma fase não existente em processos informacionais, os processos de validação e refutação de postulados de conhecimento (a diferença entre processos informacionais e de conhecimento). A ênfase em comunidades de prática, aprimoramento do aprendizado, melhor comunicação e integração está no escopo de ambas as gestões.

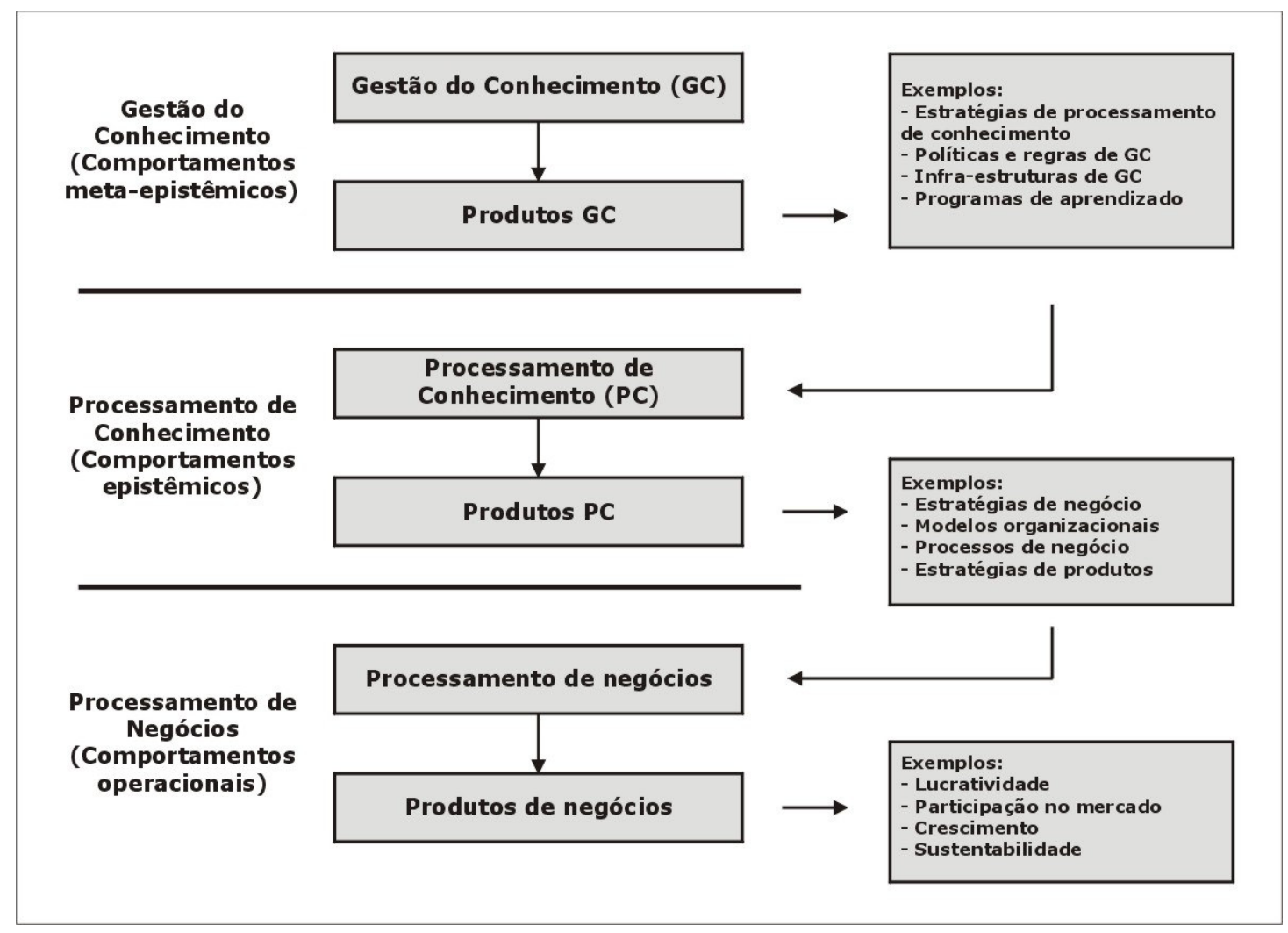

FIGURA 4 - O modelo da Nova Gestão de conhecimento

Fonte: Adaptado de Firestone e Mcelroy (2001, p. 210)

A terceira argumentação é a concepção de sistemas naturais de processamento de conhecimento (sobre os quais atuam a Gestão de Conhecimento) como sistemas adaptativos complexos, definidos como um "sistema aberto dirigido por objetivos e tentando adaptar-se a seu ambiente" (FIRESTONE e McELROY, 2001, p. 61). Segundo Holland (1997), os agentes em um sistema, simples ou compostos, são estruturalmente determinados por regras que determinam sua resposta a estímulos do ambiente (o meio e outros agentes). As mudanças nas 
estruturas baseiam-se na experiência do sistema e propiciam a adaptação. Esses sistemas são formados por sete elementos básicos: quatro propriedades e três mecanismos.

A propriedade da agregação refere-se à classificação de agentes, que podem formar metagentes, possibilitando comportamentos emergentes que transcendem os comportamentos individuais. 0 mecanismo de marcação determina destaque de características que viabilizam interações seletivas. A propriedade de fluxos abrange efeitos multiplicadores e de reciclagem de recursos. Holland (1997, p. 56) afirma que "a reciclagem de recursos através do comportamento agregado de um grupo diversificado de agentes é muito mais que a soma das ações individuais". A propriedade da diversidade é base para seleção e adaptação. Os mecanismos de modelos internos pressupõem a eliminação de detalhes e seleção de padrões externos cuja determinação enseja mudanças nas estruturas (mecanismos) dos agentes. As estruturas dos agentes constituem um modelo interno e através delas infere-se algo sobre o meio e determina-se ativamente o comportamento do agente. Esses modelos internos são habitualmente gerados pelo mecanismo de blocos (padrões e características comuns agregados).

A teoria dos sistemas adaptativos complexos repercute na doutrina de Gestão de conhecimento em foco. A quarta propriedade, a da nãolinearidade, impede ou restringe freqüentemente a aplicação de modelos determinísticos. Um princípio geral é que intervenções nos processos de conhecimento devam ser sincronizadas sob pena de serem destrutivas, já que se admite uma ordem natural emergente no sistema, de determinação impossível ou difícil (o caminho seria a procura de pontos críticos geradores de modificações estruturais). A Gestão do conhecimento é assim polarizada entre hierárquica e orgânica. ${ }^{4}$

\section{A criação de sentido}

O modelo transacional de fluxos de comportamentos entre agentes é relacionado com a criação de sentido (sensemaking) de Weick, com base em Choo (1998), Daft e Weick (1984) e Weick (1995). A criação de significado implica na escolha de um conjunto de interpretações para reduzir a ambigüidade de sinais existentes no ambiente. Interpretar engloba recortar a experiência, selecionar significados e reter interpretações racionais. Weick (1995) vê a criação de significado como um processo de construção de identidade, retrospectivo, contínuo, social, focado em pistas extraídas e governado mais pela plausibilidade do que pela precisão.

Alguns pontos em comum do sistema transacional com a criação de sentido devem ser mencionados. Agentes modificam a estrutura em processos de adaptação ao ambiente, construindo suas próprias identidades. O monitoramento, tornado equivalente à criação de sentido

4 Mac Morrow (2001), por exemplo, chama a atenção para as concepções conflitantes de Gestão do Conhecimento baseadas em um controle central ou em um respeito ao ajustamento e iniciativas naturais. 
nos ciclos de execução decisória, envolve filtragem e interpretação da realidade, não sua reflexão. A criação de sentido modela (enact) o ambiente enquanto a interação social modela a ecologia social. A criação de sentido é social, como o monitoramento, e contínua e persistente, como os ciclos de execução decisória.

Ressaltem-se duas diferenças básicas. Os autores não aceitam a idéia de construção social da realidade, mas sim sua mediação pelas motivações, predisposições, herança biológica e outros. Em segundo lugar, as reivindicações de conhecimento não seriam validadas por um consenso social, mas por testes e avaliações constantes.

\section{Capital intelectual}

A idéia inicial de Capital intelectual parte da constatação da diferença entre o valor contábil de uma organização e seu valor no mercado (MAC MORROW, 2001; STEWART, 1998). Normalmente, há uma divisão entre capital estrutural e humano. Stewart (1998) considera o capital do cliente como separado do capital estrutural. Usualmente, em sistemas de medição, como no modelo de Edvinsson e Malone, o capital intelectual é calculado por redução, totalizando um resíduo: do valor de mercado da organização subtrai-se o capital financeiro, obtendo-se o capital intelectual; extraindo-se agora o capital humano, obtém-se o estrutural, e segue-se nessa base.

Firestone e McElroy argumentam que a abordagem é equivocada por vários fatores. Tradicionalmente, metodologias do Capital intelectual tendem a valorizar objetos e produtos, entretanto o que apresenta maior valor para as organizações são os processos, ponto retratado no termo Capital de inovação social (McELROY, 2002; FIRESTONE e McELROY, 2001). Um segundo ponto é que como o princípio da não linearidade dos sistemas complexos impede a aplicação de técnicas eminentemente lineares como as contábeis, contadores deveriam introduzir sistemas de medição não-lineares adotando uma perspectiva interdisciplinar. Há realmente dois sistemas, não um. Isso significa que o valor não deve ser procurado apenas internamente à organização, mas em sistemas de valoração que abrangem interessados externos à organização. Na verdade, essa é a fonte mais importante de intangibilidade do valor da organização, o mercado. Já os sistemas internos da organização devem ser reconhecidos como sociais, complexos e emergentes. É possível gerar impactos nesses tipos de sistemas com a atuação em pontos-chave (HOLLAND, 1997), o que tornaria obsoleta a gestão convencional.

De modo geral, conclui-se que as metas da disciplina Capital intelectual ultrapassam seu estado atual. Deve haver um período de tentativa, erros e experimentação no qual teorias de produção de valores intangíveis (o direcionamento correto) possam ser testadas e avaliadas. 


\section{As melhores práticas}

Uma noção comum da Gestão do conhecimento ao longo dos últimos tempos é sua convergência com a codificação dos processos de trabalho e de suas tarefas, propiciando aos trabalhadores do conhecimento, dadas suas necessidades, acesso rápido e facilitado às chamadas melhores práticas. Argumento advindo é a afirmação da falta de contexto do problema na provisão dessas práticas codificadas.

Firestone e McElroy criticam a falta de especificação da idéia de contexto. Sistemas baseados em computador não contêm melhores práticas, mas sim reivindicações sobre melhores práticas. O raciocínio embutido na codificação de melhores práticas é bem direto: em determinadas situações, o melhor comportamento seria determinado agrupamento de ações. A condição de viabilização dessa abordagem é um procedimento de qualificação das informações de melhores práticas que passa pelo fornecimento de metareivindicações de conhecimento. Esse é o tipo de contexto passível de viabilização e necessário à avaliação das reivindicações de conhecimento: metareivindicações que possibilitem aos usuários discernimento sobre as reivindicações efetuadas, os argumentos que as fundamentam e as histórias de seus desempenhos. A abordagem que recorre ao velho chavão "a informação certa para a pessoa certa na hora certa" simplesmente supõe a existência a priori do conhecimento adequado e enfatiza o lado da oferta, não a produção do conhecimento (o lado da demanda).

\section{A tecnologia da informação}

A crítica à utilização de tecnologia de informação nos processos de gestão do conhecimento passa pelo mesmo argumento utilizado na discussão das melhores práticas. Um sistema computacional utilizado nesses processos deve efetuar a distinção entre reivindicações e metareivindicações de conhecimento e prover suporte explícito para sua avaliação. Ao ver dos autores, nenhuma aplicação desse tipo ainda existe. A tecnologia para sua construção depende de evolução na área de inteligência artificial e enfatizaria a análise e gestão de reivindicações de conhecimento em artefatos.

É concebido um portal de conhecimento empresarial que atenderia parcialmente essas condições, diferenciando informação de conhecimento, provendo metainformação e enfatizando tanto a produção com a integração de conhecimento (FIRESTONE, 2003).

\section{A cultura organizacional}

Barreiras culturais são usualmente consideradas obstáculos à transferência e compartilhamento de conhecimento em uma organização. Para realizar esses objetivos diz-se comumente que a Gestão de conhecimento deve efetuar modificações na cultura organizacional. 
A cultura é classificada pelos autores como material (Mundo 1), subjetiva (Mundo 2), definida como um conjunto emergente de predisposições de um agente grupal para perceber seu ambiente (o mesmo modelo motivacional considerado de caráter psicológico quando aplicado ao indivíduo) e objetiva (Mundo 3), definida como a configuração de orientações de valores e atitudes de alto nível expressos em um estoque de problemas emergentes, modelos, teorias, programas e histórias localizados em diversos contêineres.

A cultura é vista como onipresente na Gestão de conhecimento, processo de negócios e produtos finais. No entanto, muitos outros fatores (ecologia social, fatores situacionais, entradas transacionais), alguns deles indevidamente categorizados como culturais, contribuem para as complexas relações entre os processos de conhecimento e seus produtos. A cultura é vista pelos autores não tanto como uma resposta às dificuldades da Gestão de conhecimento, mas como um tópico com suas próprias dificuldades. Deve-se, assim, lembrar que prescrições no sentido de mudanças da cultura enfatizam um único fator explanatório dos processos de Gestão do conhecimento.

\section{A estratégia organizacional}

Firestone e McElroy defendem que ocorre constantemente na Gestão de conhecimento de primeira geração um erro de exceção da estratégia, que consiste em tornar as estratégias de negócios o ponto inicial para a estratégia de Gestão de conhecimento. Metodologias de Gestão de conhecimento seguem indevidamente os seguintes procedimentos: a) identificam a estratégia de negócio corrente; b) determinam os recursos informacionais necessários para a implementação da estratégia corrente; e c) realizam projetos de tecnologia e outros necessários para tornar os recursos informacionais facilmente acessíveis e sustentadores dos processos de negócio.

Claramente, o foco é transacional. No entanto, a estratégia deve ser encarada como um produto do processamento de conhecimento, assim como princípios, planos, modelos ou quaisquer artefatos necessários a cada um dos processos de negócios. A função da Gestão de conhecimento é aprimorar a qualidade e performance dos processos de conhecimento, não dos processos de negócios em si. Assim, ela não é subordinada à estratégia ou mesmo à sua implementação. Isso coloca a questão da localização da Gestão de conhecimento na estrutura funcional da organização. A resposta é imediata: na posição mais autônoma possível, subordinada ao grupo dos gerentes de mais alto nível da organização.

\section{Considerações finais}

A descrição do modelo de Firestone e McElroy revela características fundamentais e enseja alguns comentários críticos, assim como o discernimento de questões metodológicas consideradas básicas para a disciplina Gestão de conhecimento. 
O modelo estudado pretende ser integrativo e de amplo escopo, abrangendo tópicos afins como estratégia e cultura organizacionais, redes sociais, melhores práticas, capital intelectual, tecnologia e criação de sentido. Procura-se situar historicamente as teorias da Gestão do conhecimento, evidenciando as discordâncias e tendências. Acima de tudo, a construção da teoria dá-se por meio de interlocução crítica com outros trabalhos na área e relativização de idéias de aceitação corrente. Como resultado, vários conceitos e diferenciações freqüentemente mal estabelecidos ou omitidos na literatura sobre Gestão do conhecimento e Capital intelectual (NEHMY, 2001) são abordados pelos autores, como a diferenciação entre informação e conhecimento explícito ou entre Gestão de informação e de conhecimento.

O ponto central na concepção da teoria exposta é a validação dos postulados de conhecimento, atividade que permite a delimitação do conceito de conhecimento assim como funda as condições para a intervenção da gestão nos processos de conhecimento. É de se considerar que o mecanismo de falsificação popperiano pressupõe uma metateoria que dê conta de efetuar julgamentos das diversas reivindicações de conhecimento (PINTO, 1999). No processo de validação, influem diversos pressupostos que podem determinar resultados diferentes, o que enfraquece uma pretensão de objetivação do conhecimento. É indicativo que Firestone e McElroy provenham da área da ciência da computação, com experiência em data mining, data warehouse e inteligência artificial, e trabalhem no sentido de efetuar a tipificação dos ciclos de conhecimento organizacional em relação a processamento de postulados de conhecimento do Mundo 3 (explicitados ou passíveis de explicitação) com vista a sua validação.

De certa forma, reencontra-se aqui a tensão existente no campo da Ciência da informação ao obrigatoriamente abordar seu objeto, a informação, considerando-a em suas dimensões sociais, cognitivas e físicas - veja-se Buckland (1991), Capurro (2003) ou Miranda (2002). E, particularmente, essa tensão reflete-se na Gestão de conhecimento, disciplina que se pretende utilitária. No caso em estudo, é clara a necessidade de detalhamento de como os metaprocessos da Gestão de conhecimento podem intervir de modo efetivo em ciclos de vida do conhecimento relativos aos negócios, produzindo conhecimento útil particularmente para o processo-chave de validação dos postulados. A situação complica-se quando se leva em conta a necessidade de integração desse conhecimento, a complexidade das redes sociais transacionais e de sistemas adaptativos e o fato de postulados de mundo 2 e 3 também serem validados. Delimitar conceitualmente 0 conhecimento organizacional como postulados objetivos do mundo 3 não desonera a Gestão de conhecimento da preocupação de lidar com o mundo 2, especialmente quando se lembra que as emoções, predisposições psicológicas e crenças do mundo 2 é que são as precursoras imediatas das ações.

A par dessas observações, menos que a adesão a idéias e sua incorporação a teorias, algumas vezes realizadas apressadamente, 
interessa aqui a proposição de questões metodológicas que se evidenciaram na análise efetuada e no próprio trabalho pesquisado.

É importante uma análise criteriosa da bibliografia da área e estabelecimento de relações implícitas ou explícitas com a teoria estudada. Estudos de citações, como Serenko e Bontis (2004) ou Wilson (2002), podem ser proveitosos. A profundidade e espírito crítico na utilização de idéias da área devem ser considerados. Cabe a preocupação com tratamento dos conceitos fundamentais e estabelecimento de diferenciações básicas, como o caso mais óbvio dos conceitos de informação e conhecimento. Segue-se naturalmente a constatação do escopo das abordagens e modelos, analisando sistematicamente temas relacionados que foram enfatizados ou negligenciados (como cultura, métricas de valoração dos processos, lugar das redes sociais, etc.). Nessa perspectiva, é natural que ocorra a verificação da extensão e profundidade dos procedimentos interdisciplinares realizados. Isso implica situar os autores de outros campos e empreender uma análise, tão aprofundada quanto possível, do contexto da teoria emprestada, em termos epistemológicos e históricos. Implica também a necessidade de determinar as possíveis contradições ou reforços na apropriação dos conceitos.

Discutir as posições, motivações e intenções dos autores da área é freqüentemente um passo esclarecedor. Outras vezes a compreensão dos avanços passa pela analogia com outras teorias do campo, quando as constantes reiterações, mesmo em domínios à primeira vista díspares, indicam pontos de convergência, também de inclusão obrigatória na discussão. Esse é o caso, entre outros, do papel do hiato epistêmico ou gap de conhecimento, central à teoria estudada, assim como à perspectiva cognitivista de Belkin (1982) ou à criação de sentido de Weick (1995) ou Dervin (1992). Essa abordagem interdisciplinar coaduna-se com uma visão histórica das evoluções da disciplina Gestão do conhecimento, que evidencia as comparações, as inovações, os conflitos e os pontos necessários ao debate, além de servir como uma sólida base de assimilação de uma bibliografia fecunda, volátil e cada vez mais crítica.

\section{Referências}

ARGYRIS, C. On organizational learning. Cambridge, MA: Blackwell, 1999.

BELKIN, N. J.; ODDY, R. N.; BROOKS, H. M. ASK for Information Retrieval. Part I. Background and Theory. Journal of Documentation, v. 38, n. 2, p. 61-71, 1982.

BUCKLAND, M. Information as thing. Journal of the American Society for Information Science, v. 42, n. 5, p, 351-360, 1991.

CAPURRO, R. Foundations of information science. Review and perspectives. 2003. Disponível em: http://www.capurro.de/tampere91. htm. Último acesso em 07 jun. 2006. 
CHOO, C. W. The knowing organizational: How organizations use information to construct meaning, create knowledge, and make decisions. New York: Oxford University Press, 1998.

DAFT, R. L.; WEICK, K. E. Towards a model of organizations as interpretation systems. Academy of Management Review, v. 9, n. 2, p. 284-295, 1984.

DAVENPORT, T. H.; PRUSAK, L. Conhecimento empresarial. Rio de Janeiro: Campus, 1998.

DAVENPORT, T. H. Ecologia da informação. São Paulo: Futura, 2002.

DERVIN, B. From the mind's eye of the 'user': the sense-making qualitative-quantitative methodology. In: GLAZIER, Jack D.; POWELL, Ronald R. Qualitativy research in information management, Englewood, CO: Libraries Unlimited, 1992.

FIRESTONE, J. M. Enterprise information portals and knowledge management. Amsterdam: KMCI/Butterworth-Heinemann, 2003.

FIRESTONE, J. M.; McELROY, M. W. Key issues in The New Knowledge Management. Amsterdam: KMCI/Butterworth-Heinemann, 2001.

GETTIER, E. L. Is Justified true belief knowledge? Analysis, v. 23, p. 121$123,1963$.

HOLLAND, J. H. A ordem oculta: como a adaptação gera a complexidade. Lisboa: Gradiva, 1997.

KOENIG, M. E. D. The third stage of KM emerges. KMWorld, v. 11, n. 3, 2002.

LEONARD-BARTON, D. Nascentes do saber. Rio de Janeiro: Fundação Getúlio Vargas, 1998.

MAC MORROW, N. Knowledge Management: An introduction. Annual Review of Information Science and technology, v. 35, 2001.

McELROY, M. W. The New Knowledge Management: Complexity, Learning, and Sustainable Innovation. Amsterdam: KMCI/Butterworth-Heinemann, 2002.

Oct. 1999.

The second generation of KM. Knowledge Management, p. 86-88,

MCGEE, J.; PRUSAK L. Gerenciamento estratégico da informação. Rio de Janeiro: Elsevier, 1994.

MINTZBERG, H. The Nature of managerial Work. New York, NY: Harper \& Row, 1973.

MIRANDA, A. A ciência da informação e a teoria do conhecimento objetivo: Um relacionamento necessário. In: AQUINO, Miriam de Albuquerque (Org.). O campo da Ciência da Informação. Gênese, conexões e especificidades. João Pessoa: Ed. Universitária, 2002. 
NEHMY, R. M. Q. O ideal do conhecimento codificado na 'Era da Informação': o programa de gestão do conhecimento. 2001. Tese (Doutorado em Ciência da Informação). Belo Horizonte: Escola de Ciência da Informação, UFMG, 2001.

NONAKA, I.; TAKEUCHI, H. Criação de conhecimento na empresa: como as empresas japonesas geram a dinâmica da inovação. 12. ed. Rio de Janeiro: Elsevier, 1997.

NONAKA, I.; KROGH, G. V.; ICHIJO, K. Facilitando a Criação do Conhecimento: reinventando a empresa com o poder da inovação. Rio de Janeiro: Campus, 2001.

PINTO, P. R. M. A abordagem pragmática do conhecimento. In: VAISMAN, J.; GIRARDI, S. (Org.). A Ciência e seus impasses. Rio de Janeiro: Fiocruz, 1999.

POLANYI, M. Personal Knowledge. Chicago: University of Chicago Press, 1958.

. The Tacit Dimension. London: Routledge and Kegan Paul, 1967.

SENGE, P. M. A quinta disciplina: arte, teoria e prática da organização da aprendizagem. São Paulo: Best Seller, 1990.

SERENKO, A.; BONTIS, N. Meta-review of knowledge management and intellectual capital literature: citation impact and research productivity rankings. Knowledge and Process Management, v. 11, n. 3, p. 185-198, 2004.

SNOWDEN, D. Complex acts of knowing: paradoxes and descriptive selfawareness. Journal of knowledge Management, v. 6, n. 2, p. 1-13, 2002.

STEWART, T. A. Capital Intelectual: a nova vantagem competitiva das empresas. Rio de Janeiro: Campus, 1998.

SVEIBY, K. E. A nova riqueza das organizações. Rio Janeiro: Campus, 1998.

TARAPANOFF, K. (Org.). Inteligência organizacional e competitiva. Brasília: Ed. UnB, 2001.

WEICK, K. E. Sensemaking in Organizations. Thousand Oaks, Calif.: Sage, 1995.

WILSON, T. D. The nonsense of 'knowledge management'. Information Research, v. 8, n. 1, 2002. 